\title{
Corrupción versus auditoría forense, ante el desarrollo económico en un sistema social sin preceptos morales
}

\section{Corruption versus forensic audit, to economic development in a social system without moral precepts}

\author{
Julio Ernesto Mora Aristega ${ }^{1, *}$, Magdalena Rosario Huilcapi Masacón ${ }^{1, \dagger}$, Darwil Jorge Gil Espinoza ${ }^{1, \ddagger}$, \\ Washington Alfredo Camacho Villota ${ }^{1, \otimes}$, Nancy Elizabeth Uhsca Cuzco ${ }^{1, \diamond}$. \\ ${ }^{1}$ Universidad Técnica de Babahoyo. \\ \{jmora, mhuilcapi, dgil, wcamacho,nushca[@utb.edu.ec]\}
}

Fecha de recepción: 05 de abril de 2017 — Fecha de aceptación: 27 de junio de 2017

\begin{abstract}
Resumen-El objetivo del trabajo es conocer como la corrupción a través de los delitos de cuello blanco han influido en el desarrollo económico de las organizaciones, de tal forma que le pueda servir a las personas para informarse de esta temática no tan reciente, muy poco abordada en la sociedad común; además pretende dejar en los lectores el deseo de consultar más sobre cada una de formas de corrupción que se fraguan en las empresas y través de los cuales se forjan los fraudes; se utilizó la encuesta para poder realizar el respectivo análisis de los datos que aportan a la temática proporcionados por una muestra de cincuenta y cuatro personas que han tenido que enfrentar este tipo de problemas en calidad de gerentes de las instituciones públicas y empresas privadas de Babahoyo; llegando a concluir de que la corrupción a través de los delitos de cuello blanco mitiga el desarrollo económico empresarial, considerando que no se han aplicado los correctivos necesarios y la investigación pertinente, estas situaciones se presenta especialmente en las empresas públicas; además se determinó que la auditoría forense está relacionada con las técnicas de investigación de los delitos de cuello blanco como: malversación de bienes, coimas, fraudes, hurtos, engaños, malversación de estados financieros y evasión de impuestos; los cuales se dan por las constantes oportunidades que se presentan en las organizaciones; la auditoría forense no ha sido aplicada debido a que falta conocimiento de cómo ejecutarla.
\end{abstract}

Palabras Clave-Corrupción, Desarrollo económico, Preceptos morales, Sistema social.

\begin{abstract}
The objective of the paper is to know how corruption through white collar crime has influenced the economic development of organizations, so that it can serve the people to be informed about this subject not so recent, very little discussed in The common society; In addition it tries to leave in the readers the desire to consult more on each of forms of corruption that are forged in the companies and through which the frauds are forged; The survey was used to carry out the respective analysis of the data that contribute to the subject provided by a sample of fifty-four people who have had to face this type of problems as managers of public institutions and private companies of Babahoyo; Concluding that corruption through white-collar crime mitigates business economic development, considering that the necessary corrective measures and relevant research have not been applied, these situations arise especially in public enterprises; In addition, it was determined that forensic auditing is related to investigative techniques for white collar crimes such as: embezzlement of property, fines, fraud, theft, deception, embezzlement of financial statements and tax evasion; Which are given by the constant opportunities that are presented in the organizations; The forensic audit has not been applied due to lack of knowledge of how to execute it.
\end{abstract}

Keywords-Corruption, Economic development, Moral precepts, Social system.

\section{INTRODUCCIÓN}

$\mathbf{E}$ 1 trabajo que se ha desarrollado consiste en realizar un análisis sobre las organizaciones que se han visto afectadas por aquellas irregularidades generadas al interior de las mismas, haciendo referencia a los delitos financieros cometidos por sus directivos y empleados que son considerados de cuello blanco, esto ha generado que las organizaciones vean atrofiado su desarrollo y pierdan confianzas en los directivos y empleados; evidenciando de esta forma las debilidades de los sistemas de seguridad y de trabajo con los cuales se opera; los mismos que necesitan de la intervención de la auditoría forense para poder determinar responsabilidades, desarrollados

*Licenciado en Ciencias de la Educación, Magister en Gestión de Recursos Humanos

$\dagger$ Ingeniera Comercial, Magister en Administración de Empresas

$¥$ Contador Público Auditor, Magister en Contabilidad y Auditoría

${ }^{\otimes}$ Contador Público Auditor, Magister en Contabilidad y Auditoría

${ }^{\diamond}$ Contador Público Auditor, Magister en Tributación y Finanzas en un ambiente donde las personas que son los funcionarios de las entidades carecen de una formación axiológica en conciencia que les permita entender sus equivocaciones y las consecuencias de ellas; Estupiñán et al. (2002) indica que la auditoría forense ha mostrado su importancia demostrando que toda investigación sobre aspectos operativos, administrativos y contables requieren apoyo de contadores experimentados y con visión de detective, se ha mostrado en varias partes del mundo que los investigadores si no tienen bases contables no ayudan a determinar conclusiones básicas de apoyo a las decisiones de jueces y peritos; en este trabajo se analizan opiniones de los diversos autores que permitieron comprender la temática y que sirvieron de base para concluir y conocer más acerca de los delitos económicos o perpetrados por los delincuentes de etiqueta que abusando de la confianza convierten al engaño en una herramienta útil para el fraude; al respecto (Akers, 2013).

En este contexto investigativo se establece como hipótesis fundamental: la corrupción en un sistema social sin valores 
impide el desarrollo económico de las empresas; tomando como base el desenvolvimiento que tienen las organizaciones y los delitos de cuello blanco que se han ejecutado en ellas.

Muchas investigaciones se han realizado sobre la intervención de la auditoría forense en la solución de los delitos de cuello blanco, en empresas de todo tipo, al respecto Steinko (2013) indica que se debe a la complejidad de los delitos de cuello blanco los cuales tienden a aumentar en una economía financiarizada; en las que el principal atenuante es la carencia de preceptos morales; además de las publicaciones en diferentes medios científicos; entre ellas versan los siguientes, el artículo científico presentado por Carlos Ocampo, Omar Trejo y Guillermo Solarte Martínez, titulado: Las técnicas forenses y la auditoría; que indica que la persistente información de debilidades en sistemas de información, el lucro de fallas bien sean humanas, procedimentales o especializadas sobre infraestructuras de computación en el mundo, ofrecen un escenario perfecto para que se cultiven tendencias relacionadas con intrusos informáticos, estos poseen diferentes motivaciones, alcances y estrategias que desconciertan a analistas, consultores y cuerpos de investigadores especiales, pues sus modalidades de ataque y penetración de sistemas varían de un caso a otro, en este momento, es preciso establecer un nuevo conjunto de herramientas, estrategias y acciones para descubrir en los medios informáticos, la evidencia digital que sustente y verifique las afirmaciones que sobre los hechos delictivos se han materializado en el caso bajo estudio (Ocampo et al., 2010).

Otra investigación realizada es el artículo científico presentado por Allan Errol Rozas Flores, Docente Asociado de la Facultad de Ciencias Contables de la Universidad Nacional Mayor de San Marcos, titulado: Auditoría Forense, que en resumen indica: La auditoría forense es una auditoría especializada en la obtención de evidencias para convertirlas en pruebas, las cuales se presentan en el foro; es decir en las cortes de justicia, con el propósito de comprobar delitos o dirimir disputas legales. Actualmente se vienen desarrollando importantes esfuerzos mediante auditorías de cumplimiento y auditorías integrales que deben ser reforzadas con procedimientos legales de investigación, para minimizar la impunidad que se presenta ante delitos económicos y financieros, como la corrupción administrativa, el fraude corporativo y el lavado de dinero y activos. Prevenir, detectar, investigar y comprobar estos delitos, requiere de habilidades y conocimientos profundos en materia contable y financiera, jurídica, e investigativa, que faciliten obtener las pruebas convincentes que requiere la justicia para sus sentencias. Los tipos de fraude que consideran los auditores cuando auditan los estados financieros son básicamente: informes financieros fraudulentos y malversación de activos. En estos tiempos en los que las empresas se encuentran más expuestas a los fraudes, el auditor es contratado para revisar aspectos de control, para descubrir los factores que originan los fraudes y recomendar los programas para mitigarlos, ayudar a que éstos se presenten de manera poco frecuente o su nivel sea bajo (Rozas Flores, 2009).

El tema de los delitos económicos ya no es tan novedoso, cada vez se torna más frecuente, a pesar de los controles que las empresas imponen, sus funcionarios empleados de confianza y gerentes son los que más se abocan a cometerlos, es frecuente que una sociedad que ha evolucionado tanto y en la cual la tecnología ha hecho que los empleados tengan acceso a información confidencial se perpetúen a través de coaliciones empresariales los llamados delitos financieros, surge entonces la interrogante, ¿Cómo controlar estos hechos? la cual es difícil de responder.

Diversas son las definiciones y el tratamiento de aspectos importantes de auditoría forense y su trabajo en relación a los delitos de cuello blanco, sus actores y su perfil, Serpa (2014) desde la perspectiva de varios autores, se han presentado a través de los años; en las cuales cada uno trata de manifestar lo que a su criterio refleja este término; es así:

El término forense corresponde al latín forensis, que significa público, sin embargo y complementando su significado se puede remitir a su origen forum del latín que significa foro, plaza pública o de mercado en las antiguas ciudades romanas donde se trataban las asambleas públicas y los juicios, lo forense se vincula con lo relativo al derecho y la aplicación de la ley, en la medida en que se busca que un profesional idóneo asista al juez en asuntos legales que le competan y para ello aporte pruebas de carácter público para presentar en el foro, para los tiempos actuales, en la corte (Cano and Castro, 2002).

Por otra parte se considera a la auditoría forense como el otro lado de la medalla de la labor del auditor, en procura de prevenir y estudiar hechos de corrupción. Como la mayoría de los resultados del auditor van a conocimiento de los jueces, es usual el término forense. Como es muy extensa la lista de hechos de corrupción, conviene señalar que la auditoría forense, para profesionales con formación de contador público, debe orientarse a la investigación de actos dolosos en el nivel financiero de una empresa, el gobierno o cualquier organización que maneje recursos, al respecto OCDE (2015) indica que es esencial llevar a cabo exámenes rigurosos e independientes que contribuyan a garantizar la aplicación de las disposiciones legales y reglamentarias en materia de integración y lucha contra la corrupción dentro de las organizaciones.

Además la auditoría forense es entendida como el proceso de recopilar, evaluar y acumular evidencia con la aplicación de normas, procedimientos y técnicas de auditoría, finanzas y contabilidad para la investigación de ciertos delitos a los que se ha de llamar "financieros" o "de cuello blanco" (Chavarría and Roldán, 2009).

En este tipo de delincuencia no se han definido las características particulares, dado que en las diferentes figuras penales concurren elementos diversos de difícil agrupamiento, los delitos se profundizan según Chavarría and Roldán (2009) a partir de dos características:

- Una parte importante del material probatorio o de la evidencia para demostrar la existencia del delito, se obtienen a partir de la evaluación de los sistemas de control interno, la revisión de los registros y los documentos contables, financieros y/o administrativos, que sirven de comprobantes de transacciones realizadas entre personas físicas y/o jurídicas (Chavarría and Roldán, 2009). 
- La acción delictuosa ocasiona una disminución, susceptible de cuantificación en términos monetarios, en el patrimonio de la persona, física o jurídica, víctima del delito. (Chavarría and Roldán, 2009).

La auditoría forense es una auditoría especializada en descubrir, divulgar y atestar sobre fraudes y delitos en el desarrollo de las funciones públicas y privadas; es en términos contables, la ciencia que permite reunir y presentar información financiera, contable, legal, administrativa e impositiva, para que sea aceptada por una corte o un juez en contra de los perpetradores de un crimen económico; convirtiéndose de esta manera en una fuente de evidencia total para que los delitos económicos no queden impune (Cano and Castro, 2002).

Un compromiso de auditoría forense involucra por 10 menos: análisis, cuantificación de pérdidas, investigaciones, recolección de evidencia, mediación, arbitraje y testimonio como un testigo experto. (Ocampo et al., 2010), a continuación se detallan las principales formas de fraudes utilizando los estados financieros:

Tabla 1. Modalidad de fraude con los estados financieros

\begin{tabular}{|c|c|}
\hline MODALIDAD & PRÁCTICA \\
\hline $\begin{array}{l}\text { Registro de } \\
\text { ingresos } \\
\text { ficticios }\end{array}$ & $\begin{array}{l}\text { - Registrar,ventas de bienes o servicios que no han } \\
\text { ocurrido. } \\
\text { - Involucrar clientes falsos. } \\
\text { - Registrar ingresos de clientes legítimos con facturas } \\
\text { que se elaboran y no se tramitan. } \\
\text { - Reversar los ingresos ficticios en el siguiente } \\
\text { periodo. } \\
\text { - Sobrevalorar,artificialmente las facturas de clientes } \\
\text { reales. }\end{array}$ \\
\hline $\begin{array}{l}\text { Operaciones } \\
\text { ficticias } \\
\text { en periodo } \\
\text { de corte }\end{array}$ & $\begin{array}{l}\text { - Registrar ingresos o gastos en periodos que } \\
\text { no corresponden. } \\
\text { - Trasladar ingresos o gastos entre periodos, } \\
\text { con el fin de incrementar o disminuir utilidades. } \\
\text { - Registrar ingresos futuros sin la certeza de } \\
\text { su materialización. } \\
\text { - Registrar cobranzas o litigios que no están } \\
\text { resueltos. } \\
\text { - Contabilizar contratos a largo plazo como } \\
\text { ya percibidos o viceversa. }\end{array}$ \\
\hline $\begin{array}{l}\text { Valuación } \\
\text { incorrecta } \\
\text { de activos }\end{array}$ & $\begin{array}{l}\text { - Contabilizar activos de largo plazo como de corto } \\
\text { plazo. } \\
\text { - Sobrevalorar cuentas por cobrar o inventarios a } \\
\text { expensas de los activos de largo plazo. } \\
\text { - Sobrevalorar activos fijos y otros activos. } \\
\text { - Incrementar los costos unitarios. } \\
\text { - Omitir el traslado de inventarios al costo de ventas. } \\
\text { - Manipular registros extracontables para justificar } \\
\text { asientos fraudulentos. } \\
\text { - Dejar de reconocer cartera de difícil cobro con el } \\
\text { fin de no disminuir el saldo de las cuentas por cobrar. } \\
\text { - Registrar activos o activos fijos en forma ficticia. } \\
\text { - Valorar incorrectamente los activos. }\end{array}$ \\
\hline $\begin{array}{l}\text { Obligaciones } \\
\text { y gastos } \\
\text { ocultos }\end{array}$ & $\begin{array}{l}\text { - Omitir pasivos y gastos. } \\
\text { - Contabilizar gastos como activos. } \\
\text { - Omitir el registro de gastos y deudas con terceros. } \\
\text { - Ocultar facturas, extractos o cuentas de cobro y en } \\
\text { un periodo distinto solicitarlas de nuevo a proveedores. } \\
\text { - Registrar inversiones de capital como gastos. } \\
\text { - Registrar en periodos diferentes devoluciones y dto. } \\
\text { con el fin de presentar mayores ventas netas. }\end{array}$ \\
\hline $\begin{array}{l}\text { Información } \\
\text { complementaria, } \\
\text { incompleta } \\
\text { o,inexacta }\end{array}$ & $\begin{array}{l}\text { - Omitir la divulgación de información relacionada } \\
\text { con pasivos. } \\
\text { - Omitir el informe de obligaciones contingentes. } \\
\text { - Ocultar a la junta directiva, asamblea o junta de } \\
\text { socios, los fraudes o indicios de fraude encontrados. }\end{array}$ \\
\hline
\end{tabular}

Fuente: Artículo científico elaborado por (Leal Rodríguez ,

Rodríguez Patiño, \& González Garzón, 2010)
Al respecto Bareño-Dueñas (2009) en su artículo mecanismos de contabilidad para prevenir y detectar el lavado de activos en Colombia, explica la importancia de ver en la auditoría forense el elemento alternativo para mejorar los mecanismos de contabilidad existentes, ya que ésta debe ir enfocada no sólo a detectar sino también a prevenir.

Un aspecto complementario de la auditoría forense es la contabilidad, la cual suministra pruebas, esto es, toda la información financiera y no financiera documentada que utiliza y provee la contabilidad que pueda servir en la consecución de una investigación de fraude, disputas legales, entre otras. La forma como se obtiene esa información es lo que hace la diferencia de catalogar la parte forense como auditoría o como contabilidad, considerando que los procesos llevados a cabo para la revisión y evaluación de documentos probatorios deben seguir el marco normativo para desarrollar la auditoría (Ramírez and Piedrahita, 2012)., de esta forma en la tabla dos detallada a continuación se exponen las modalidades de fraude a través de la malversación de bienes dentro de la organización:

Tabla 2. Modalidades en malversación de bienes

\begin{tabular}{|c|c|}
\hline MODALIDAD & PRÁCTICA \\
\hline $\begin{array}{l}\text { Malversación } \\
\text { en ingreso } \\
\text { de dinero }\end{array}$ & $\begin{array}{l}\text { - Sustraer dineros recaudados antes de su ingreso al } \\
\text { sistema transaccional y de su registro en la contabilidad. } \\
\text { - Hurtar dineros cuando ya se encuentran registrados } \\
\text { y han afectado la contabilidad. }\end{array}$ \\
\hline $\begin{array}{l}\text { Malversación } \\
\text { en desembolso } \\
\text { de dinero }\end{array}$ & $\begin{array}{l}\text { - Elaborar y utilizar cheques de la empresa para } \\
\text { beneficio personal, con ayuda de cómplices. } \\
\text { - Adulterar cheques ya elaborados, creando formas para } \\
\text { que en su proceso de entrega y pago puedan ser } \\
\text { alterados. } \\
\text { - Comprar productos o adquirir servicios que no ingresan. } \\
\text { - Utilizar un beneficiario cómplice, quien sirve de } \\
\text { recolector del producto de los fraudes con esta modalidad. }\end{array}$ \\
\hline $\begin{array}{l}\text { Malversación } \\
\text { de activos } \\
\text { en el ciclo de } \\
\text { compras y } \\
\text { adquisiciones }\end{array}$ & $\begin{array}{l}\text { - Crear empresas fachadas con todos los requisitos para } \\
\text { cerrar el ciclo fraudulento } \\
\text { - Elaborar facturas falsas. } \\
\text { - Diseñar procesos engañosos para hacer probar } \\
\text { desembolsos ilícitos. } \\
\text { - Manipular o falsificar documentos y firmas en, los } \\
\text { soportes de las compras. } \\
\text { - Concentrar la contratación de servicios por su carácter } \\
\text { de intangibilidad. } \\
\text { - Utilizar empresas ficticias para hacer intermediación } \\
\text { y obtener beneficios } \\
\text { con la venta de productos o serviciosa un precio mayor } \\
\text { del que ofrece el proveedor original. }\end{array}$ \\
\hline $\begin{array}{l}\text { Fraudes en } \\
\text { la nómina }\end{array}$ & $\begin{array}{l}\text { - Omitir pasivos y gastos. } \\
\text { - Contabilizar gastos como activos. } \\
\text { - Omitir el registro de gastos y deudas con terceros. } \\
\text { - Ocultar facturas, extractos o cuentas de cobro y en un } \\
\text { periodo distinto solicitarlas de nuevo a los proveedores. } \\
\text { - Registrar inversiones de capital como gastos. } \\
\text { - Registrar en periodos diferentes devoluciones y } \\
\text { descuentos con el fin de presentar mayores ventas netas. }\end{array}$ \\
\hline $\begin{array}{l}\text { Malversación } \\
\text { de bienes } \\
\text { inventario } \\
\text { y otros activos }\end{array}$ & $\begin{array}{l}\text { - Utilizar indebidamente los bienes de la organización } \\
\text { para beneficio particular. } \\
\text { - Hurtar bienes. } \\
\text { - Adulterar el resultado de la toma física y compensarlo } \\
\text { con cuentas de otras ventas. }\end{array}$ \\
\hline
\end{tabular}

Fuente: Artículo científico elaborado por (Rodríguez et al., 2010)

Instituto de Auditores Internos del Ecuador (2013) en la Guía para la Práctica Auditoría Interna y Fraude indican que el fraude comprende una amplia gama de irregularidades y actos ilegales caracterizados por la intensión de engañar o 
proporcionar falsa información, en el marco internacional para la práctica profesional del Instituto de Auditores Internos, definen al fraude como:

Cualquier acto ilegal caracterizado por engaño, ocultación o violación de la confianza. Estos actos no requieren la aplicación de amenaza, de violencia o de fuerza física. Los fraudes son perpetrados por individuos y por organizaciones para obtener dinero, bienes o servicios o para asegurarse ventajas personales o de negocios. (Instituto de Auditores Internos del Ecuador, 2013)

Es innegable que los fraudes o delitos económicos permanecerán como una de las principales preocupaciones para las empresas por sus múltiples variantes, la amplia gama de defraudadores, la variedad de recursos que se utilizan y cada vez su mayor sofisticación. Sin duda, no existe hasta el momento una solución universal para este problema, pero la mejor forma de detenerlo es compartir experiencias y conocimientos sobre el tema que permitan hacerle frente (Rodríguez et al., 2010)., en un análisis de fraudes financieros perpetrados por importantes empresas a comienzos del siglo XXI, concluyen que inversionistas, bancos, proveedores y empleados, se han visto afectados por el engaño, pues han confiado fielmente en la información de las instituciones, que usaron diferentes estratagemas diseñadas por propietarios, autoridades y personal de confianza para crear "estructuras de la mentira", generando profundos vacíos económicos y sociales (Elliot and Schroth, 2003).

Todos los delitos de cuello blanco a los que se hace referencia en este trabajo cumplen con las características indicadas en la definición de fraude que antecede, por lo tanto un fraude realizado de esta manera es un delito de cuello de blanco; Veiga (2011) al respecto algunos autores incluyendo abogados hacen referencia a ellos; así se encuentra: Zambrano Pasquel (2012) quien afirma "que en una sociedad animada por el deseo de crecimiento y expansión económica, aparece y se incrementa la delincuencia de cuello blanco, constituida por infracciones cometidas exclusivamente por personas de alto nivel socioeconómico, acomodadas y de buena reputación, que abusan del ejercicio de sus actividades, en procura de llegar a un enriquecimiento que por vías morales y legales es inalcanzable".

El debate sobre los medios de lucha más eficaces para la minimización de este flagelo no se detiene. Actualmente, cuando tanto la opción represiva general como los actuales catálogos de sanciones penales no parecen efectivos contra la delincuencia económica, la criminología propone posibles soluciones al respecto, las que, sin negar la importancia de la sanción penal, enfatizan en las medidas profilácticas que se deben implementar (Barroso González, 2015); la concentración de control penal en los delitos roscos, marginaliza e invisibiliza la ausencia de persecución a los delitos de los poderosos, también conocidos como cuello blanco (Pérez Álvarez and Díaz Cortés, 2014).

Un carácter muy importante de los delitos de cuello blanco, consiste en la gran dificultad que existe para que sean descubiertos y sancionados, en razón entre otras cosas del poderío económico de quienes los cometen (Derecho, 2015); estos son falsos delincuentes de cuello blanco o de etiqueta. (Zambrano

\section{Pasquel, 2012)}

Cuando se estudia a la delincuencia organizada bajo los rubros de delincuencia de cuello blanco o ïnstitucionalizada", aparecen en el esquema criminológico como sujetos activos, personas de cierta preparación cultural, social y económica, que abusan del poder sabiendo de antemano que casi siempre esta forma delictiva es impune, al respecto se observa una ausencia casi completa de reproche social relacionado con la condena penal de un hombre de negocios. (Saggese et al., 2016) Esto se explica por cierta solidaridad del medio, por la diferencia instintiva que el público establece entre la criminalidad violenta y la delincuencia astuta y porque se llega a considerar al delincuente de cuello blanco como un hombre sin la suerte que tienen los demás (Zambrano Pasquel, 2012).

Sutherland en su obra El Ladrón Profesional un clásico respecto a la temática; indica que el ladrón profesional no considera a la sociedad en general como un enemigo o perpetra crímenes contra la sociedad debido al odio hacia la misma. El ladrón tiene la idea de ganar dinero y debe necesariamente hacerlo de la sociedad. Las únicas personas que pueden ganar dinero con el grupo antisocial son los policías, abogados, tramitadores y políticos. En lugar de odiar a la sociedad, el ladrón profesional se regocija en el bienestar del público, le gustaría ver a la sociedad disfrutar de la prosperidad continua porque entonces sus propios intereses, naturalmente serán mayores.

Geis (2006) afirma que en los círculos criminológicos, el estudio del delito de cuello blanco quedó relegado frente a la preocupación por formas de actos ilícitos como los delitos de violencia y la delincuencia juvenil, asuntos que lógicamente se considera poseen una relevancia más inmediata y dramática respecto a las vidas diarias de las personas comunes.

Las personas que cometen delitos de cuello blanco son asistidas por abogados de prestigio y trayectoria; así mismo, los jueces y fiscales que tienen a su cargo estas causas son presionados para "dormir" los expedientes, con lo cual, pasados algunos años, la causa caduca y la impunidad finalmente se establece (Ragagnin, 2005).

En los delitos de cuello blanco se encuentran: sobornos, fraudes, estafas, malversación o desviación de fondos, tráfico de influencias, incumplimientos y otras corruptelas, cometidos por hombres de negocios respetablesz profesionales de cierto prestigio social, como empresarios, banqueros, políticos, magistrados, entre otros, los cuales se caracterizan por: lesionar la confianza en el tráfico comercial; llevar un comportamiento abusivo frente al desconocimiento o ingenuidad de su víctima y una planificación de la acción delictiva que le permite evitar su descubrimiento (Ríos Boyan, 2014).

En la auditoría forense las estrategias, procedimientos y métodos investigativos son especialmente estudiados con el fin de preservar y priorizar el interés público, un auditor interno o externo puede tener mucha experiencia en los procesos de evaluación del control interno y de presentación de informes con valor agregado ante el ente que contrata sus servicios, pero para el caso de investigaciones de fraudes y delitos requiere conocimientos en el campo judicial, especialmente en el levantamiento de indicios y evidencias (Cano and Castro, 2002). 
Los procedimientos ejecutados por la auditoría forense como son de tipo investigativo y lo que se persigue es la judicialización y a la postre la penalización o exoneración, deben ser ejecutados bajo normas internacionales de auditoría especial; para no cometer errores que por insignificantes que puedan ser anulen totalmente la investigación y el caso en la Corte o Tribunal de Justicia pueda ser desestimado por un juez (Cano and Castro, 2002); es por estas razones que la auditoría forense se convierte en una herramienta eficaz para la investigación cuando se comete un delito, pero también sirve de control y prevención, pues no necesariamente está concebida para encontrar un hecho delictivo sino también para esclarecer la verdad de los hechos y exonerar de responsabilidad a un sospechoso que sea inocente o a una empresa o entidad que haya sido acusada de un fraude con la intención de obtener beneficios económicos.

Por lo tanto es así como el desarrollo de la auditoría forense en torno al fraude contable, encadena una serie de procedimientos: jurídicos (tipificación del fraude, manejo de la cadena de custodia, informe pericial, evidencia probatoria); de auditoría, normas internacionales de auditoría emitidas por la Federación Internacional de Contadores; y procedimientos contables (Ramírez and Reina Bohórquez, 2013).

De allí se desprende que el fraude o engaño intencional es una estrategia para lograr una meta personal $u$ organizacional o para satisfacer una necesidad humana; sin embargo, un objetivo de necesidad puede ser satisfecho por medios honestos, así como por medios deshonestos. Cuando la competencia es aguda y depredadora, la deshonestidad puede racionalizarse rápidamente, el engaño, por lo tanto puede convertirse en un arma en cualquier concurso de supervivencia. Dicho de otra manera, la lucha por sobrevivir a menudo genera un comportamiento engañoso (Singleton et al., 2006).

De acuerdo a los datos de la tabla detallada a continuación se establece que los niveles de fraude en las organizaciones son perpetrados por los mismos empleados, sin distinción de niveles jerárquicos, sin embargo el máximo impacto en las pérdidas se refleja en los más altos ejecutivos, de allí se desprende la expresión de cuello blanco.

Tabla 3. Pérdidas por fraude por nivel ocupacional.

\begin{tabular}{|c|c|c|}
\hline FRECUENCIA & CARGO & IMPACTO \\
\hline $10 \%$ & $\begin{array}{c}\text { Ejecutivos de } \\
\text { máximo nivel }\end{array}$ & $\begin{array}{c}75 \% \text { de pérdidas } \\
\text { en dinero por } \\
\text { fraude. }\end{array}$ \\
\hline $30 \%$ & Gerentes y jefes & $\begin{array}{c}20 \% \text { de } \\
\text { pérdidas en } \\
\text { dinero } \\
\text { por fraude. }\end{array}$ \\
\hline $60 \%$ & $\begin{array}{c}\text { Empleados de bajo } \\
\text { y medio nivel } \\
\text { pérdidas } \\
\text { generales. }\end{array}$ \\
\hline \multicolumn{2}{|c|}{ Fuente: Association of Certified Fraud Examiners. }
\end{tabular}

A pesar de lo duro y los efectos de los fraudes la ciudadanía frecuentemente muestra una tolerancia casi generalizada ante los delitos económicos, a la llamada delincuencia de cuello blanco, por la escasa incidencia o afectación directa a los bienes jurídicos personales. Por otra parte, los niveles elevados de inteligencia del infractor han llevado a un aumento de la cifra negra de estas tipologías delictivas, lo que resulta aún más pernicioso y comparable con el efecto iceberg, donde lo más nocivo se encuentra oculto (Puebla and Fonticoba, 2013).

El perjuicio económico provocado por la delincuencia económica es cuantioso y unido a ello, trae consigo además la pérdida de confianza en el tráfico mercantil, en la credibilidad de las instituciones del Estado y en los funcionarios públicos (Puebla and Fonticoba, 2013).

La auditoría forense se enfoca en la prevención y detección del fraude financiero a través de los siguientes enfoques: preventivo es proactivo y está orientado a proporcionar aseguramiento o asesoría a las organizaciones respecto de su capacidad para disuadir, prevenir, detectar y reaccionar ante fraudes financieros y detectivo se orienta a identificar la existencia de fraudes financieros mediante la investigación profunda de los mismos llegando a establecer: cuantía del fraude, efectos directos e indirectos, posible tipificación; presuntos autores, cómplices y encubridores

El objetivo de esta investigación es determinar cómo la corrupción en un sistema social sin valores impide el desarrollo económico de las empresas y la opinión respecto a este tipo de delincuencia, de tal forma que le pueda servir a las personas que lo lean para informarse de esta temática no tan reciente, pero muy poco abordada en la sociedad común.

Este trabajo pretende dejar en los lectores especialmente los que estén trabajando en las áreas administrativas un deseo de consultar más sobre cada uno de los delitos de cuello blanco que se fraguan en las empresas.

\section{Metodología}

La metodología usada en el trabajo consistió en: utilizar una encuesta a cincuenta y cuatro gerentes de las instituciones públicas y empresas privadas de Babahoyo, en la que se plantean preguntas de opción que apuntan a descubrir el grado de como la corrupción impide el desarrollo económico de las empresas; como estructura básica de la investigación la cual ha permitió determinar la presencia de los delitos de cuello blanco en las mismas y los niveles de afectación en el desarrollo económico.

\section{RESULTADOS Y Discusión}

Luego realizar una profunda lectura de la bibliografía citada, analizar los aspectos más importantes y de aplicar las técnicas de recolección de la información descritas en la parte metodológica, se han obtenido los siguientes resultados:

Como puede apreciarse en la tabla cuatro la mayor responsabilidad de los encuestados se encuentra en aspectos financieros lo que incluye el manejo de recursos monetarios y negociaciones; facilitando así el escenario para el cometimiento de fraudes en la organización. Rozas Flores (2009) indica que el fraude abarca un conjunto de irregularidades y actos ilegales caracterizados por el engaño intencional, puede ser cometido en detrimento de la organización y por personas externas o internas de la misma, considerando esta posición los gerentes tienen la obligación de fortalecer sus acciones para cumplir con sus responsabilidades. 
Tabla 4. Responsabilidades de los gerentes

\begin{tabular}{|c|c|c|}
\hline Responsabilidades & Frecuencia & $\%$ \\
\hline Financieras & 23 & 42,6 \\
\hline Gerenciales & 11 & 20,4 \\
\hline Comercialización & 7 & 13,0 \\
\hline Responsabilidad Social & 3 & 5,5 \\
\hline Servicios Público & 10 & 18,5 \\
\hline Total & 54 & 100 \\
\hline
\end{tabular}

Fuente: Encuesta aplicada a gerentes de empresas públicas y privadas de Babahoyo.

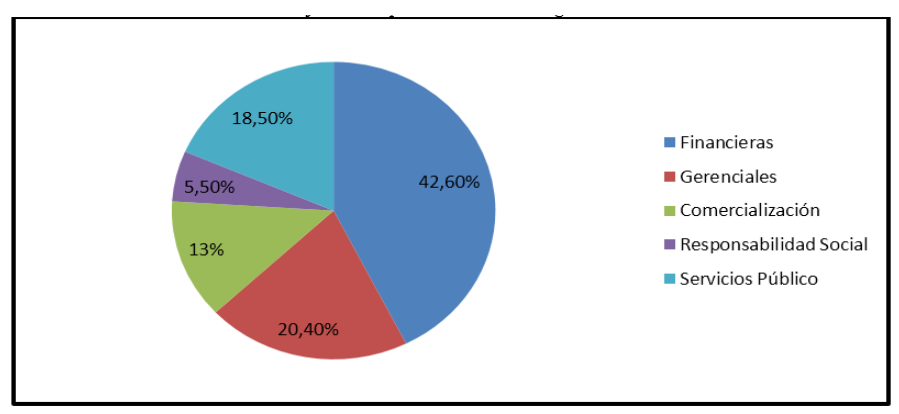

Figura 1. Responsabilidades de los gerentes

Fuente: (Encuesta nacional de empleo, desempleo y subempleo Diciembre 2015)

La tabla cinco muestra los problemas o delitos de cuello blanco que se dan en las organizaciones, cuyo mayor impacto lo generan las coimas, situación que en la sociedad actual ha sido considerada como normal, a pesar del conocimiento de los funcionarios, los proveedores o usuarios de la prohibición y de las sanciones que generan, de la misma forma Pineda Villavicencio (2015) en la Investigación del Delito de Lavado de Activos, indica que se consideren los programas de auditoria donde se incluirán específicamente los objetivos y procedimientos para cada rubro o hecho que va a evaluar el auditor, a fin de obtener evidencia que le permita determinar el desbalance patrimonial en las personas naturales y jurídicas en proceso investigativo de delitos.

Tabla 5. Delitos de cuello blanco evidenciados en la organización.

\begin{tabular}{|l|c|c|}
\hline \multicolumn{1}{|c|}{ Delitos } & Frecuencia & \% \\
\hline Malversación de bienes & 12 & 22,2 \\
\hline Coimas & 15 & 27,7 \\
\hline Fraudes, hurtos, engaños. & 3 & 5,6 \\
\hline Malversación de estados financieros & 5 & 9,3 \\
\hline Evasión de impuestos & 10 & 18,5 \\
\hline Otros & 9 & 16,7 \\
\hline \multicolumn{1}{|c|}{ Total } & 54 & 100 \\
\hline
\end{tabular}

Fuente: Encuesta aplicada a gerentes de empresas públicas y privadas de Babahoyo.

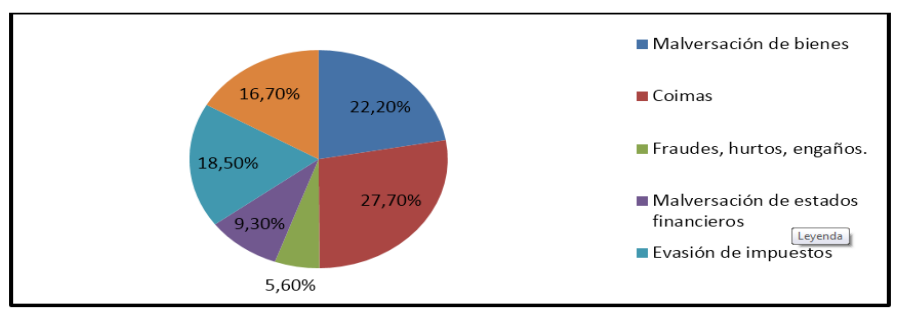

Figura 2. Delitos de cuello blanco evidenciados en la organización.

Fuente: Encuesta aplicada a gerentes de empresas públicas y privadas de Babahoyo.

La tabla seis muestra la frecuencia con las que se presentan las oportunidades de fraude a los gerentes, los cuales manifiestan en su mayoría que las oportunidades para el fraude están siempre, debido a que los usuarios intentan sobornar a los funcionarios por recibir un privilegio en la atención que por derecho les corresponde o recibirlo más rápido; los mismos proveedores son capaces de ofrecer cuantiosas coimas $\mathrm{u}$ ostentosos obsequios a los gerentes y a los empleados por lograr ventas y cumplir con su meta o incrementar sus comisiones; haciéndoles ver que todos se beneficiarán de un proceso que de acuerdo a su criterio no causa daño a nadie; al respecto (Ríos Boyan, 2014) indica que en la categoría de fraudes se encuentran todas las conductas criminales que ocasionan un daño, bien sea de manera intencional o por negligencia, así como aquellos hechos en donde se valen de las computadoras como método, medio o símbolo para la comisión del ilícito; en este contexto es necesario reconocer la obligación que tienen las organizaciones de fortalecer sus controles internos y sus medios de seguridad para combatir la corrupción.

Tabla 6. Presentación de oportunidades de fraude.

\begin{tabular}{|c|c|c|}
\hline Presentaciones de oportunidades & Frecuencia & $\%$ \\
\hline Siempre & 25 & 46,3 \\
\hline Frecuentemente & 16 & 29,6 \\
\hline A veces & 10 & 18,5 \\
\hline Rara vez & 3 & 5,6 \\
\hline Nunca & 0 & 0,0 \\
\hline Total & 54 & 100 \\
\hline \multicolumn{3}{|c|}{$\begin{array}{l}\text { Fuente: Encuesta aplicada a gerentes de empresas } \\
\text { públicas y privadas de Babahoyo. }\end{array}$} \\
\hline
\end{tabular}

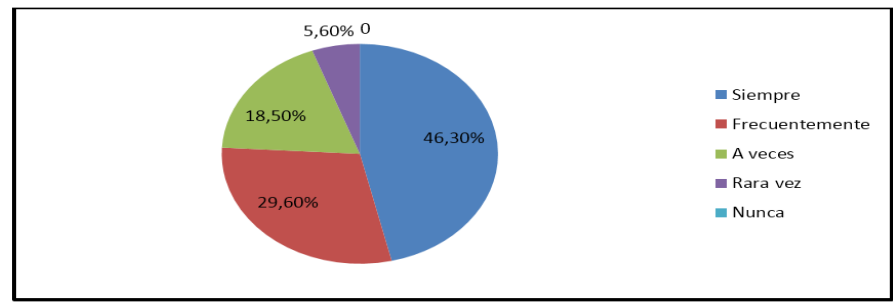

Figura 3. Presentación de oportunidades de fraude.

Fuente: Encuesta aplicada a gerentes de empresas públicas y privadas de Babahoyo.

La tabla siete indica que en la mayoría de las organizaciones tomadas como muestra, no han realizado auditoría en los últimos años, debido a que en las instituciones públicas tienen 
que ser parte del programa anual de la Contraloría General del Estado; por ello un $63 \%$ de estas organizaciones no han sido auditadas, este escenario de no analizar las acciones financieras y administrativas que ejecutan las organizaciones hace que se de espacio y se fortalezcan las colusiones para el fraude, facilitando el trabajo a los perpetradores de cuello blanco; Ramírez and Piedrahita (2012) manifiesta que caracterizar la evidencia desde el punto de vista de la auditoría implica establecer procedimientos que proporcionen guías suficientes y pertinentes sobre lo que constituye evidencia para castigar los delitos de cuello blanco; es necesario que los gerentes tomen asunto en este tipo de delitos, ya que son en extremo peligrosos y pueden llevar a las empresas al declive.

Tabla 7. Aplicación de los tipos de auditoría en los últimos años.

\begin{tabular}{|c|c|c|}
\hline Auditoría & Frecuencia & $\%$ \\
\hline Financiera & 2 & 3,6 \\
\hline Operativa & 5 & 9,3 \\
\hline De gestión & 6 & 11,1 \\
\hline Forense & 0 & 0,0 \\
\hline General & 7 & 13,0 \\
\hline Ninguna & 34 & 63,0 \\
\hline Total & 54 & 100 \\
\hline
\end{tabular}
públicas y privadas de Babahoyo.

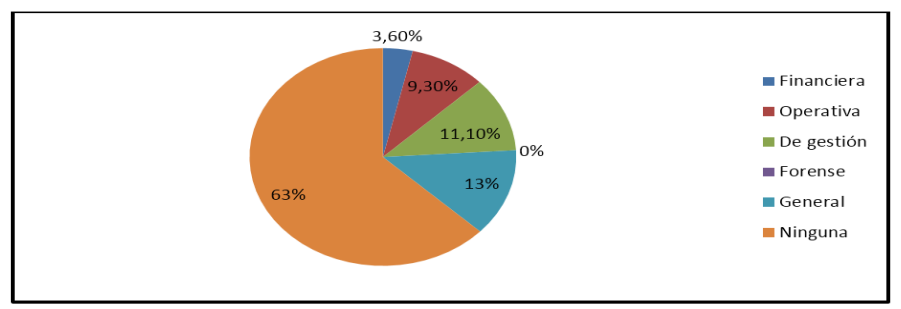

Figura 4. Aplicación de los tipos de auditoría en los últimos años. Fuente: Encuesta aplicada a gerentes de empresas públicas y privadas de Babahoyo.

La tabla ocho muestra los distintos niveles de desarrollo empresarial en el que se determina que el $59 \%$ de las organizaciones tomadas como base para este estudio no han generado un desarrollo empresarial, debido a las afectaciones por los delitos de cuello blanco que se han presentado en ellas, la mayoría públicas, que presentan corrupción en la entrega de servicios; y en otra parte las privadas en las que el delito más común es la coima, que se ha convertido en un problemas general a nivel público, impulsado por las personas que buscan un beneficio de la organización; Estupiñán et al. (2002) afirma que las necesidades económicas nacen principalmente de costumbre humana, se modifican generando posibilidades de empresa y lógicamente riesgos los cuales deben ser coordinados entre los administrativos y de control; en este panorama corresponde a las empresas hacer un esfuerzo por mejorar os controles utilizando los preceptos de la auditoría forense para asegurar la información y los recursos de la organización.
Tabla 8. Efectos en el desarrollo económico por delitos de cuello blanco.

\begin{tabular}{|c|c|c|}
\hline Niveles de desarrollo empresarial & Frecuencia & $\%$ \\
\hline Alto desarrollo & 0 & 0,0 \\
\hline Desarrollo normal & 12 & 22,2 \\
\hline Desarrollo medio & 10 & 18,5 \\
\hline Bajo desarrolloForense & 21 & 38,9 \\
\hline Ningún desarrollo & 11 & 20,4 \\
\hline Total & 54 & 100 \\
\hline
\end{tabular}

Fuente: Encuesta aplicada a gerentes de empresas públicas y privadas de Babahoyo.

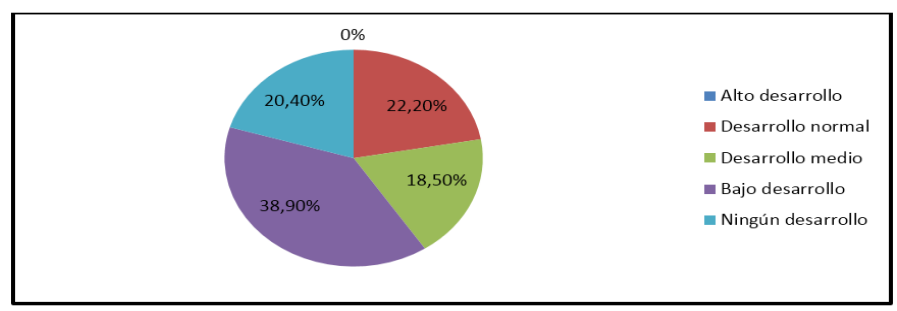

Figura 5. Efectos en el desarrollo empresarial por delitos de cuello blanco.

Fuente: Encuesta aplicada a gerentes de empresas públicas y privadas de Babahoyo.

\section{Conclusiones}

Los delitos de cuello blanco que se ejecutan en las empresa públicas y privadas de Babahoyo afectan el desarrollo económico en un alto grado, debido a que no se han aplicado los correctivos necesarios y la investigación pertinente, este tipo de situaciones se presenta especialmente en las empresas públicas en las que el control interno es más débil y las oportunidades de fraude por insignificantes que parezcan están a la orden del día.

La auditoría forense está relacionada con las técnicas de investigación de los delitos de cuello blanco tales como: malversación de bienes, coimas, fraudes, hurtos, engaños, malversación de estados financieros y evasión de impuestos que es una de las más comunes Green (2013) los cuales se dan por las constantes oportunidades que se presentan en las organizaciones públicas y privadas; la auditoría forense no ha sido aplicada debido a que falta conocimiento sobre su ejecución.

Los escasos preceptos morales de las personas que laboran en las empresas dan pie para que se presenten oportunidades de fraude a los gerentes y a los empleados; en el sector privado en que la competencia es fuerte sobre todo por la situación económica, los mismos proveedores y representantes de empresas privadas ofrecen cuantiosas coimas, obsequios y privilegios a empleados y gerentes por lograr cumplir con sus presupuestos de ventas para incrementar sus comisiones; haciéndoles ver que todos se beneficiarán de un proceso que de acuerdo a su criterio no causa daño a nadie, pero que está tipificado como delitos de cuello blanco.

\section{Bibliografía}

Akers, R. L. (2013). La generalidad de la teoría del autocontrol: una primera extensión de la teoría general del delito a 
los países de habla hispana, volume 28. Editorial Dykinson, SL.

Bareño-Dueñas, S. M. (2009). Mecanismos de contabilidad para prevenir y detectar el lavado de activos en colombia. Cuadernos de contabilidad, 10(27):341-357.

Barroso González, J. L. (2015). Los delitos económicos desde una perspective criminológica. Revista IUS, 9(35):95-122.

Cano, M. and Castro, R. M. (2002). Auditoría forense. articulo publicado por el Instituto de Auditores Internos.

Chavarría, J. and Roldán, M. (2009). Auditoría Forense. Madrid: Kapeluz.

Derecho, L. D. (2015). Cuello blanco y delito. 138:57-87.

Elliot, L. A. and Schroth, R. J. (2003). Cómo mienten las empresas: ¿ por qué Enron es tan sólo la punta del iceberg?: una guía para comprender el fraude contable y la ingeniería financiera. Gestión 2000.

Estupiñán, G. et al. (2002). Control interno y fraudes con base en los ciclos transaccionales. Technical report.

Geis, G. (2006). El delito de cuello blanco como concepto analítico e ideológico. Derecho penal y criminología como fundamento de la política criminal. Estudios en homenaje al Prof. A. Serrano Gómez, Dykinson, Madrid, page 320.

Green, S. P. (2013). Mentir, hacer trampas y apropiarse de lo ajeno: una teoría moral de los delitos de cuello blanco. Marcial Pons.

Instituto de Auditores Internos del Ecuador (2013). Guía para la Práctica: Auditoría Interna y Fraude.

Ocampo, C. A., Trejos BuriticÁ, O. I., and Solarte Martinez, G. R. (2010). Las técnicas forenses y la auditoría. Scientia Et Technica, 16(45).

OCDE, S. O. (2015). Marco de acción para la inversión.

Pérez Álvarez, F. and Díaz Cortés, L. M. (2014). Moderno discurso penal y nuevas tecnologías: memorias [del] III Congreso Internacional de Jóvenes Investigadores en Ciencias Penales, 17, 18 y 19 de junio de 2013, volume 207. Ediciones Universidad de Salamanca.

Pineda Villavicencio, G. A. (2015). Efectos de la auditoría forense en la investigación del delito de lavado de activos en el perú, 2013-2014.

Puebla, I. G. and Fonticoba, T. D. A. (2013). La ejecución de las sanciones en los delitos de cuello blanco. Misión Jurídica. Revista de Derecho y Ciencias Sociales, 6(6):95107.

Ragagnin, F. I. (2005). El relato de las noticias sobre delito de cuello blanco. la criminalidad de etiqueta. Palabra Clave, (13).

Ramírez, A. E. L. and Piedrahita, V. S. (2012). La auditoría forense: un campo en potencia. Adversia, (8):55-66.

Ramírez, M. and Reina Bohórquez, J. (2013). Metodología y desarrollo de la auditoría forense en la detección del fraude contable en colombia. Cuadernos de Administración (Universidad del Valle), 29(50):177-195.

Ríos Boyan, O. R. (2014). Auditoria forense fraudes contables y delitos de cuello blanco. Revista Ventana Cientifica, page 60 .

Rodríguez, L. A. L., Patiño, E. R., and Garzón, R. E. G. (2010). Auditoría forense: los procedimientos del contador público en la investigación del fraude corporativo. Gestión
\& Sociedad, 3(2):141-160.

Rozas Flores, A. (2009). Auditoria forense "forensic audit". Revista de la Facultad de Ciencias Contables, 16(32):73101.

Saggese, S. B., Sánchez, B. J. F., and Basaldúa, J. I. E. (2016). Estudios de Derecho Penal: Homenaje al profesor Miguel Bajo. Editorial Centro de Estudios Ramon Areces SA.

Serpa, I. (2014). El dilema de las operaciones grises: Modus operandi de la delincuencia económica para lavar el dinero sucio. Editorial Dunken.

Singleton, T. W., Singleton, A. J., Bologna, G. J., and Lindquist, R. J. (2006). Fraud auditing and forensic accounting. John Wiley \& Sons.

Steinko, A. F. (2013). Delincuencia, finanzas y globalización, volume 35. CIS-Centro de Investigaciones Sociológicas.

Veiga, J. M. F. (2011). Investigación del fraude interno y externo en el ámbito corporativo (aseguradoras) e institucional: en búsqueda de los porqué, cuándo y cómo: Referencia especial al arson y al tráfico ilícito de vehículos. Editorial Club Universitario.

Zambrano Pasquel, A. (2012). El delito de cuello blanco. 